\title{
VULNERABILIDADE NO DESENVOLVIMENTO DA CRIANÇA: INFLUÊNCIA DAS INIQUIDADES SOCIAIS
}

\author{
Vulnerability in child development: influence of social \\ inequities
}

\author{
Vulnerabilidad en el desarrollo del niño: la influencia de las \\ iniquidades sociales
}

Artigo Original

\section{RESUMO}

Objetivo: Conhecer a compreensão do enfermeiro da Estratégia Saúde da Família sobre a vulnerabilidade no desenvolvimento da criança. Métodos: Pesquisa exploratória, qualitativa, realizada com 39 enfermeiros que atuavam em Unidades de Saúde com Estratégia Saúde da Família, em Curitiba, Paraná, Brasil. O estudo ocorreu no período de setembro de 2011 a dezembro de 2012. Para coleta de dados, utilizou-se a entrevista semiestruturada, e como referencial metodológico, a hermenêutica dialética, de cuja análise emergiram as categorias empíricas: precariedades na inserção social das famílias, iniquidades na ocupação do solo, dificuldades de acesso à proteção e promoção social e suas contradições. Resultados: $\mathrm{O}$ enfermeiro da Estratégia Saúde da Família compreende como elementos de vulnerabilidade no desenvolvimento da criança as iniquidades sociais: baixa escolaridade dos pais, desemprego, baixa renda, ausência de saneamento básico, situação precária da estrutura das construções, e falta de acesso à profissionalização, programas sociais e vagas nas creches. Conclusão: O enfermeiro compreende que a vulnerabilidade no desenvolvimento infantil está relacionada a elementos de ordem socioeconômica e sua compreensão extrapola os componentes biológicos e individuais a respeito do desenvolvimento infantil.

Descritores: Vulnerabilidade em Saúde; Desenvolvimento Infantil; Saúde da Criança; Enfermagem.

\section{ABSTRACT}

Objective: To know the comprehension of Family Health Strategy nurses about the vulnerability in child development. Methods: Exploratory qualitative research carried out with thirty-nine (39) nurses, which worked at 39 Health Units running the Family Health Strategy in Curitiba, Paraná State, Brazil. The study took place from September 2011 to December 2012. For data collection, semi-structured interview was used, and dialectical hermeneutics as a methodological framework, from whose analysis emerged the empirical categories: precariousness in the families' social insertion, inequities in land occupation, difficulties of access to social protection and promotion, and their contradictions. Results: Family Health Strategy nurses understand as elements of vulnerability in child development the social inequities: low parental education, unemployment, low income; absence of basic sanitation, precarious situation of the building structure, and lack of access to professionalization, social programs, and vacancies in the kindergartens. Conclusion: The nurse understands that the vulnerability in child development is related to elements of socioeconomic nature, and their comprehension of vulnerability exceeds the biological and individual components regarding child development.

Descriptors: Health Vulnerability; Child Development; Child Health; Nursing.

\author{
Daniel Ignacio da Silva ${ }^{(1)}$ \\ Liliana Muller Larocca ${ }^{(2)}$ \\ Maria Marta Nolasco Chaves ${ }^{(2)}$ \\ Verônica de Azevedo Mazza ${ }^{(2)}$
}

1) Universidade de São Paulo - USP - São Paulo (SP) - Brasil

2) Universidade Federal do Paraná - UFPR Curitiba (PR) - Brasil

Recebido: $15 / 09 / 2014$ Revisado: 17/11/2014 Aceito: 23/01/2015 


\section{RESUMEN}

Objetivo: Conocer la comprensión del enfermero de la Estrategia de Salud de la Familia sobre la vulnerabilidad en el desarrollo del niño. Métodos: Investigación exploratoria y cualitativa realizada con 39 enfermeros que actuaban en Unidades de Salud con Estrategia de Salud de la Familia en Curitiba, Paraná, Brasil. El estudio se dio entre septiembre de 2011 y diciembre de 2012. Se utilizó la entrevista semiestructurada para la recogida de datos y la hermenéutica dialéctica como referencial metodológico de cuya análisis surgieron las siguientes categorías empíricas: las precariedades en la inserción social de las familias, las iniquidades de la ocupación del suelo, las dificultades de acceso a la protección y promoción social y sus contradicciones. Resultados: El enfermero de la Estrategia de Salud de la Familia comprende como elementos de vulnerabilidad para el desarrollo del niño las iniquidades sociales: la baja escolaridad de los padres, el desempleo, la baja renta, la ausencia de saneamiento básico, la situación precaria de estructura de las construcciones y la falta de acceso a la profesionalización, los programas sociales y las plazas en las guarderías. Conclusión: El enfermero comprende que la vulnerabilidad en el desarrollo infantil está relacionada con los elementos del orden socioeconómico y su comprensión sobrepasa los componentes biológicos e individuales respecto el desarrollo infantil.

Descriptores: Vulnerabilidad en Salud; Desarrollo Infantil; Salud del Niño; Enfermería.

\section{INTRODUÇÃO}

As crianças que habitam nações em desenvolvimento e são submetidas a condições socioeconômicas adversas são mais vulneráveis a vários agravos, pelo fato de serem geradas em gestações de risco ${ }^{(1)}$. Tais situações de vulnerabilidade determinam o comprometimento do crescimento e desenvolvimento dessas crianças. Devido a esse pressuposto, identificam-se evidências da influência de elementos biológicos, psicossociais e ambientais dos indivíduos e seus familiares sobre o seu desenvolvimento( ${ }^{(2)}$.

As precárias condições econômicas constituem situações de vulnerabilidade que, em certas circunstâncias, não estão isoladas, pois permeiam o relacionamento dos pais da criança, colaborando para aumentar os conflitos entre eles, com reflexos diretos no relacionamento com o filho - fenômeno que se denomina como miséria afetiva $a^{(3-4)}$.

Uma situação com estímulos inadequados e insuficientes compõe um espaço de vulnerabilidade, passível de ser minimizado por um ambiente apoiador, definido como o conjunto de relacionamentos sustentadores contínuos e interações afetuosas que são necessários para que a criança tenha um desenvolvimento cerebral adequado $^{(3-5)}$. A ausência desse ambiente apoiador pode prejudicar a maturação dos circuitos cerebrais, sistemas metabólicos reguladores, havendo interrupção dos órgãos de desenvolvimento e aumento das probabilidades de ocorrerem, em longo prazo, problemas de aprendizagem, comportamento, como também o comprometimento da saúde física e mental da criança ${ }^{(5)}$.

Para se identificar uma criança vulnerável, é necessário que se verifique a inter-relação da condição do meio social no qual ela habita, com sua condição orgânica ${ }^{(2)}$. A miséria, advinda da iniquidade social, é considerada uma situação que aumenta significativamente a vulnerabilidade da criança, podendo originar subnutrição, carência social e prejuízos nas atividades educacionais, bem como incide diretamente no bem-estar infantil, configurando-se como barreira para seu desenvolvimento ${ }^{(4)}$.

Neste estudo, o desenvolvimento humano pode ser conceituado como um processo de mudança e continuidade nas características psicobiológicas da criança, para a aquisição de novas competências que contribuem para sua sobrevivência e autonomia durante a vida ${ }^{(6)}$. Esse processo ocorre como uma "função conjunta das características do ambiente e da pessoa em desenvolvimento"(6:145).

Nessa perspectiva, a vulnerabilidade no desenvolvimento da criança pode ser compreendida como um complexo de condições que torna a criança susceptível a sofrer prejuízos ou atrasos em seu desenvolvimento devido à influência de elementos de natureza individual, social e programática, os quais são denominados situações $\operatorname{adversas}^{(7)}$.

Esta pesquisa mostra-se relevante para a reorientação da prática profissional das equipes de saúde, pois a apreensão da vulnerabilidade permite aos profissionais reconhecerem as necessidades de saúde de sujeitos ou comunidades sob seu cuidado, tornando possíveis intervenções mais apropriadas para suas realidades ${ }^{(8)}$. Da mesma forma, sua aplicação na atenção à saúde da criança possibilita a reorientação do modelo assistencial para a superação do conceito biológico e reducionista a respeito do desenvolvimento infantil ${ }^{(7,10)}$.

De acordo com o modelo conceitual de vulnerabilidade no desenvolvimento infantil, a vulnerabilidade social é caracterizada pela inserção social da família e pelo seu acesso às políticas de promoção e proteção social ${ }^{(7,9)}$. Essas situações são descritas pela inserção da família na produção e, consequentemente, na reprodução social. Esta é refletida na perspectiva da inserção no emprego, na garantia de renda, no acesso à escolaridade e às condições habitacionais, pois são processos que potencializam a vulnerabilidade ${ }^{(10-12)}$. Assim como pelo acesso desse segmento populacional aos serviços de saúde, educação, assistência social e à garantia dos direitos humanos e de cidadania. Considerase que tais condições refletem diretamente na promoção 
do desenvolvimento infantil, assim como na autonomia e capacidade decisória das famílias ${ }^{(10,11)}$.

Dessa forma, o objetivo do estudo foi conhecer a compreensão do enfermeiro da Estratégia Saúde da Família sobre a vulnerabilidade no desenvolvimento da criança.

\section{MÉTODOS}

Trata-se de uma pesquisa exploratória, quantitativa, realizada em 39 Unidades Municipais de Saúde (UMS) com Estratégia Saúde da Família (ESF), localizadas em cinco distritos sanitários da cidade de Curitiba, Paraná, Brasil, as quais pertenciam a territórios que apresentavam, concomitantemente, os resultados de Indicadores de Inserção Social (IIS) e de Qualidade do Domicílio (IQD) iguais ou inferiores à média apresentada nos nove distritos que compõem o território municipal ${ }^{(10)}$. Os distritos sanitários escolhidos, conforme os critérios já estabelecidos, foram: Cajuru, Boqueirão, Bairro Novo, Pinheirinho e CIC.

Participaram do estudo 39 enfermeiros, sendo 37 $(n=37)$ do sexo feminino e $2(n=2)$ do sexo masculino, que compunham as equipes multiprofissionais das UMS referidas anteriormente. Fizeram parte do estudo enfermeiros com mais de dois anos completos atuando na ESF e lotação na área de maior risco social e epidemiológico da unidade. Assim, foi entrevistado um enfermeiro em cada UMS, escolhido intencionalmente. Aqueles que concordaram assinaram o Termo de Consentimento Livre e Esclarecido.

Para o recrutamento dos participantes, solicitou-se à autoridade sanitária da UMS que indicasse, mediante o planejamento local, a área de sua adscrição que tivesse maior risco social e epidemiológico, bem como o enfermeiro responsável por essa área. Escolheram-se essas áreas por permitirem uma maior aproximação com a vulnerabilidade social e programática ${ }^{(7)}$.

Realizou-se contato prévio com as autoridades sanitárias de 43 UMS para a pesquisa, porém, houve aceitação para participação em 39 unidades. Entre as quatro UMS que não participaram, teve-se que: em duas UMS, houve recusa dos próprios enfermeiros em aceitar participar; em uma UMS, não havia enfermeiro lotado na área de maior risco social e epidemiológico; e em uma UMS, todos os enfermeiros tinham menos de dois anos de experiência na ESF.

A coleta dos dados ocorreu no período de fevereiro a março de 2012, por meio de entrevistas individuais semiestruturadas. As entrevistas abordaram situações e elementos que prejudicavam o desenvolvimento infantil na perspectiva do enfermeiro, situações de prejuízos no desenvolvimento infantil presenciadas pelo enfermeiro, e ações de promoção ao desenvolvimento infantil desenvolvidas pelo enfermeiro. As falas dos participantes foram analisadas de acordo com a hermenêutica dialética ${ }^{(12)}$.
A hermenêutica dialética pode ser definida como uma forma de interpretação crítica e emancipadora dos fenômenos humanos, por meio da compreensão e do sentido que vêm do passado. Tal referencial pressupõe que não há consenso e ponto de chegada ao processo do conhecimento, pois apreende que a construção da ciência ocorre por meio de uma relação dinâmica entre a razão dos sujeitos e a objetividade de sua práxis ${ }^{(12)}$.

Para operacionalizar a hermenêutica dialética, este estudo seguiu os seguintes passos metodológicos: ordenação dos dados - mediante a transcrição das gravações das entrevistas, releitura do material e organização dos relatos em determinada ordem, com o início da classificação ${ }^{(12)}$; classificação dos dados - por meio da leitura exaustiva e repetida dos textos, que permitiu a apreensão das ideias centrais e a construção de categorias empíricas ${ }^{(12)}$ a partir das categorias analíticas estabelecidas na matriz de análise da vulnerabilidade da criança diante de situações adversas ao seu desenvolvimento ${ }^{(7)}$.

Finalmente, ocorreu a análise final, na qual foi realizado um processo de inflexão sobre as falas dos enfermeiros, como ponto de partida e de chegada. A partir dessa inflexão, ocorreu um movimento constante do empírico para o teórico e vice-versa, havendo um processo entre o concreto e o abstrato, entre o particular e o geral ${ }^{(12)}$. O resultado final da análise foi a concretude da práxis dos enfermeiros como sujeitos epistêmicos, expressa em categorias empíricas na dimensão da vulnerabilidade da criança. Este estudo apresenta as categorias empíricas que são da dimensão social da vulnerabilidade: precariedades na inserção social da família, iniquidades na ocupação do solo, dificuldades de acesso à proteção e promoção social e suas contradições.

As categorias empíricas encontram-se sintetizadas nas Figuras 1, 2 e 3, permitindo a apreensão do leitor sobre os elementos presentes na vivência dos enfermeiros que influenciam o desenvolvimento da criança e sobre quais são as condições existentes na dimensão estrutural que demonstram a contradição ou negação dos elementos vivenciados pelos sujeitos ${ }^{(12)}$.

Os dados foram coletados pelo discente participante do estudo, do sexo masculino, que recebeu capacitação metodológica para realizar as entrevistas em disciplina específica. Ele não possuía nenhum vínculo pessoal ou profissional com os participantes da pesquisa.

Nas unidades de registro, os respondentes foram apresentados e identificados com a abreviação (E) e numerados sequencialmente, a fim de garantir o anonimato dos participantes. Esta pesquisa atendeu às normas nacionais de ética em pesquisa envolvendo seres humanos e obteve a aprovação do Comitê de Ética do Setor de Ciências da Saúde da Universidade Federal do Paraná, sob o registro n. 1170.095.11.6. 


\section{RESULTADOS E DISCUSSÃO}

Este material foi extraído de uma pesquisa que abordou as dimensões individual, social e programática da vulnerabilidade da criança ${ }^{(7)}$, todavia, este manuscrito explorou particularmente a dimensão social da vulnerabilidade no desenvolvimento da criança. Seguem, neste espaço, a descrição e discussão das categorias empíricas que emergiram da análise final do método hermenêutico dialético.

\section{Precariedades na inserção social da família}

Nesta primeira categoria, os participantes, convergentemente, destacaram a baixa escolaridade dos pais como um dos elementos da inserção social da família:

"A questão do nível escolar, ela não entende o que você está falando, por mais que você faça desenhinho, solzinho, luazinha, bolinha [...].” (E18)

"Os pais vêm de culturas que não tem escolaridade [...]." (E3)

A situação de desemprego foi considerada codependente à baixa escolaridade. Os entrevistados a compreenderam como aspecto significativo da inserção social:

"O desemprego é muito grande, [...] as pessoas que moram aqui nessa área da beira do rio são excluídas." (E23)

"Então algumas falam: 'Ah, doutora, eu estou desempregada, o marido está desempregado' [...].” (E26)

$\mathrm{Na}$ mesma perspectiva contida na situação de desemprego, a baixa renda foi citada pelos enfermeiros como outro aspecto da inserção social da família:

"Porque são famílias de baixa renda mesmo." (E9)

"A mãe não tem o que comer e mal divide um leite, que ela pega do governo, para cinco ou dez filhos. " (E30)

Os participantes se referem à baixa escolaridade como fator gerador de dificuldades na compreensão de prescrições que pode comprometer o cuidado à criança e a efetivação de estímulos ao desenvolvimento infantil ${ }^{(13)}$. Esses dados estão de acordo com um estudo que mostrou a existência de associação entre a escolaridade da mãe e sua capacidade de estimular o desenvolvimento da criança ${ }^{(4)}$.

A inflexão dialética das falas dos participantes permitiu relacionar a baixa escolaridade dos cuidadores com a situação da população na qual este estudo foi desenvolvido, composta em grande parte por migrantes provenientes de regiões rurais do estado do Paraná e de outras regiões do país. A maioria foi para a capital do estado em busca de emprego e melhores condições de vida, devido ao modelo econômico vigente no Paraná, que está baseado no latifúndio e na exportação de commodities agrícolas ${ }^{(14)}$. Portanto, existem diferenças notáveis entre grupos populacionais quanto ao local de moradia, refletidas na escolaridade, uma vez que os habitantes das zonas rurais estudam menos que os da área urbana ${ }^{(15,16)}$.

Devido aos determinantes estruturais apontados, a inflexão dialética mostrou que resultados dessa categoria estão relacionados à realidade de muitas famílias brasileiras que se encontram segregadas de sua cidadania ${ }^{(17)}$. A baixa escolaridade média da população e as desigualdades permanentes de acesso à educação têm se constituído uma contradição da política educacional em muitos países ${ }^{(15)}$, o que mantém ativo o debate sobre a urgência de universalização da educação básica nos aspectos quantitativos e qualitativos, assim como a eliminação do analfabetismo, por meio de políticas públicas, como a educação de jovens e adultos ${ }^{(16)}$.

A interpretação dialética correlacionou as situações vivenciadas pelos enfermeiros em sua realidade particular com condições da realidade geral, como a precariedade do emprego para além da baixa escolaridade. Pôde-se apreender essa situação com uma política de geração de empregos subordinada a uma vertente neoliberal na estrutura da economia mundial, que reflete diretamente na vida de todas as pessoas ${ }^{(18)}$. Tal situação se mostrou mais frequente após a década de 1990, devido às “[...] significativas mudanças na composição setorial da ocupação ocorridas no mercado de trabalho urbano durante a década de 1990, em particular, a significativa expansão do setor de serviços e a contração da indústria de transformação"(19:598).

Entende-se o desemprego no Brasil como uma contradição das políticas econômicas que privilegiaram a estabilidade monetária e fomentaram a alta rotatividade da força de trabalho e a concorrência exagerada entre os trabalhadores na luta pelas escassas vagas de trabalho abertas $^{(18)}$. Portanto, a fim de cumprir suas metas de ajustes macroeconômicos, o Estado neoliberal aumenta o desemprego e diminui a participação do trabalho assalariado no total das ocupações, reduzindo o trabalho assalariado com carteira assinada no total da população economicamente ativa. De forma similar, os governos adotam medidas que flexibilizam e desregulamentam o mercado de trabalho para reduzir o "custo Brasil", objetivando melhorar a competitividade externa e o lucro do grande capital ${ }^{(19)}$.

Destarte, as situações particulares vivenciadas pelos enfermeiros expressam a situação geral de miséria e pobreza que assola grande parte dos brasileiros, estabelecendo um alto nível de desigualdade social ${ }^{(17)}$. A situação de vida na periferia dos grandes centros urbanos muitas vezes não permite o acesso de seus moradores aos bens de consumo, o 
que reflete os efeitos deletérios das políticas neoliberais em curso, como metas de inflação, juros altos, câmbio flexível e superávit primário(17,19).

A inflexão dialética remeteu às situações de baixa escolaridade, desemprego e baixa renda, referidas pelos enfermeiros, para a exclusão social, a qual vitimiza muitos brasileiros e se constitui uma contradição direta, perversa e irreversível do neoliberalismo econômico vigente no sistema produtivo brasileiro, com destaque para aspectos relacionados a emprego, condições e relações de trabalho, padrões de consumo, padrão de vida e proteção social ${ }^{(19)}$. A elevação da dívida pública brasileira, associada com o desemprego e a dificuldade de mobilidade social, compeliu o Estado a investir em programas sociais de transferência de renda focados na massa miserável da população ${ }^{(17,19)}$.

A Figura 1 sintetiza o processo de inflexão dialética e indica que as precariedades na inserção social da família podem causar dificuldades de entendimento dos cuidadores quanto às orientações dos profissionais de saúde, assim como prejuízos na provisão de sustento material para o atendimento das necessidades da criança e a promoção do seu desenvolvimento ${ }^{(9-11)}$.
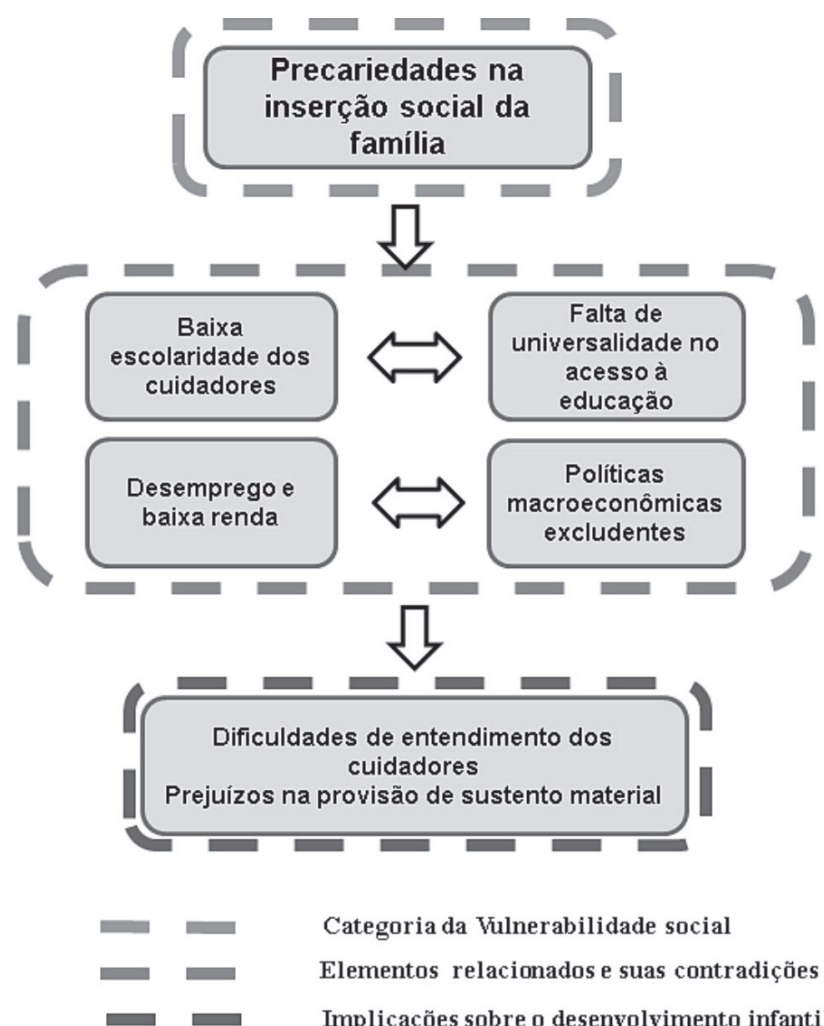

Categoria da Vulnerabilidade social

Elementos relacionados e suas contradições

Implicações sobre o desenvolvimento infantil

Figura 1 - Precariedades na inserção social da família, elementos relacionados e contradições apreendidas com suas implicações sobre desenvolvimento da criança, segundo os enfermeiros da ESF. Curitiba-PR, 2012.

\section{Iniquidades na ocupação do solo}

Nesta segunda categoria, os participantes relatam que as iniquidades na ocupação do solo são caracterizadas pela ausência de saneamento básico:

"Condições também de saneamento, porque ali é uma área de invasão, não tem saneamento básico." (E4)

"Questões das ruas que não estão canalizadas, muito esgoto a céu aberto, [...] crianças com leptospirose, positivas, por conta de falta de saneamento básico primário." (E18)

Em outras falas, os enfermeiros apontam a situação precária da estrutura das construções como elemento que prejudica a saúde das crianças:

“[...] Porque a casa não tem forro." (E19)

"As moradias [...] são de papelão, de lona, e lá dentro tem um bebezinho." (E31)

"[...] São todos moradores da beira do rio. Então são taperas [casas de adobe] mesmo." (E21)

Os enfermeiros descrevem a falta de saneamento como um elemento que pode influenciar na qualidade de vida da criança. Essas declarações corroboram com um estudo que evidenciou que as condições habitacionais influenciam a incidência e prevalência de doenças específicas e discorreu sobre a habitação como um fator socioeconômico que possui implicações sobre a saúde ${ }^{(20)}$. Entre os Determinantes Sociais em Saúde (DSS), a falta de abastecimento de água, de rede de esgoto e de destino de lixo pode influenciar a saúde e o desenvolvimento infantil ${ }^{(11,21)}$.

A inflexão dialética relacionou essa situação particular de más condições habitacionais, referida pelos enfermeiros, à situação geral de precariedade das condições insalubres de moradia em muitas cidades. A sobrevivência na área urbana é condicionada fundamentalmente pelo acesso à moradia, que é um direito essencial, como a saúde, renda e educação ${ }^{(22)}$.

Essas situações particulares mostram a contradição gerada pelas iniquidades nas formas de produção e apropriação da habitação e do ambiente urbano pelos diferentes grupos sociais, e apontam para a rápida urbanização do território brasileiro não simplesmente como um processo demográfico ${ }^{(21)}$. As baixas condições habitacionais mostram a contradição da urbanização da população, que se converte em um processo de privilégios de parte da população inserida em atividades econômicas mais relevantes ${ }^{(22,23)}$

A inflexão crítica mostrou que as baixas condições habitacionais estão relacionadas a situações estruturais e gerais, como a posse da terra e dificuldade de acesso à infraestrutura e bens de serviços e consumo que permitam uma qualidade de vida para os habitantes do solo ${ }^{(22)}$. No 
entanto, deve-se considerar que a ocupação do solo e sua habitação é fruto de um processo histórico de produção capitalista, caracterizado pela produção privada, que alcança somente uma parcela da sociedade. Tal produção social é formada pela classe alta ou média alta, que se apropria dos espaços territoriais que apresentam condições adequadas de acessibilidade às áreas centrais das cidades e melhores condições de infraestrutura ${ }^{(23,24)}$. Essa desigualdade está, em grande parte, ligada ao processo veloz de urbanização de países em desenvolvimento, como o Brasil, que se mostrou muito superior à dos países capitalistas mais avançados ${ }^{(23)}$. Esse crescimento excessivo das grandes metrópoles, impulsionado pelas políticas capitalistas, gerou iniquidades na ocupação do solo, restringindo-o a uma parte da população, e formou ilhas de desenvolvimento, rodeadas de áreas de ocupação irregular, compostas por favelas, cortiços e loteamentos clandestinos $^{(24)}$.

A Figura 2 sintetiza o processo de inflexão dialética e demonstra que as iniquidades na ocupação do solo podem expor a criança aos agravos diarreicos e respiratórios, trazendo prejuízos à sua saúde e, consequentemente, ao seu desenvolvimento ${ }^{(11,21)}$.

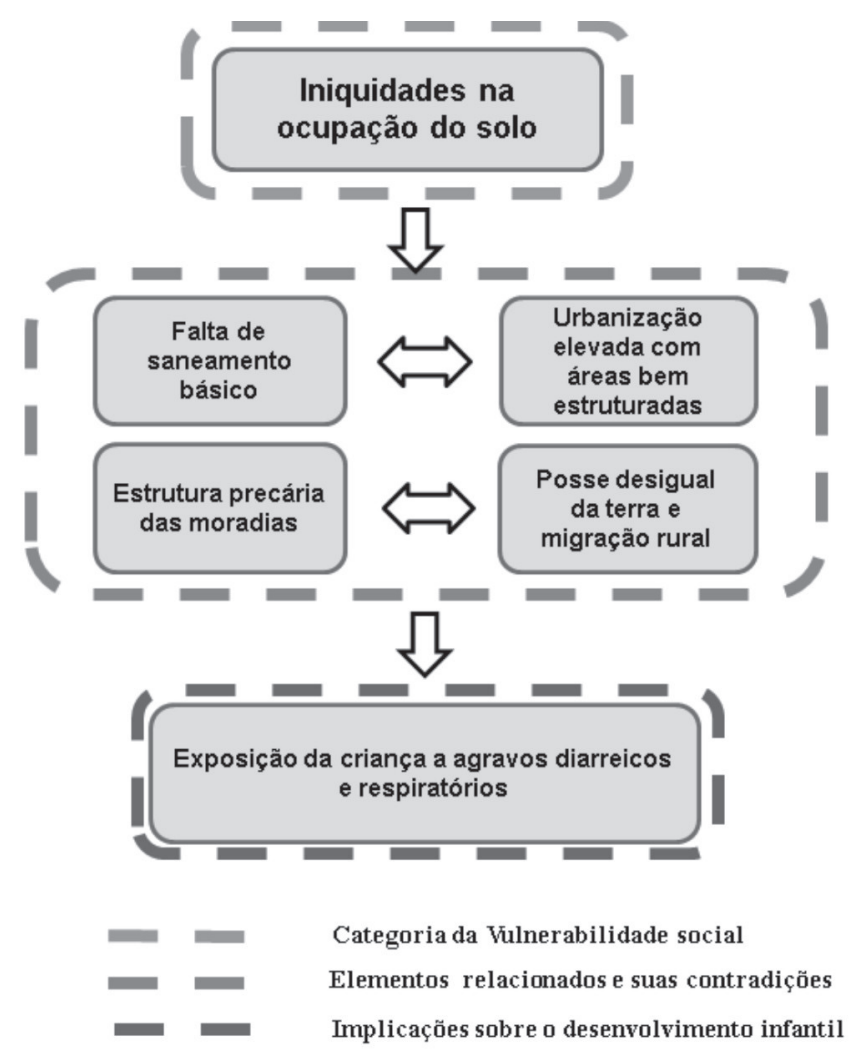

Figura 2 - Iniquidades na ocupação do solo, elementos relacionados e contradições apreendidas com suas implicações sobre desenvolvimento infantil, segundo os enfermeiros da ESF. Curitiba-PR, 2012.

\section{Dificuldades de acesso à proteção e promoção social}

$\mathrm{Na}$ terceira e última categoria, o enfermeiro compreende que a dificuldade de acesso da criança e de sua família à proteção e promoção social é um elemento que pode prejudicar o cuidado da família à criança. As principais dificuldades relatadas são a falta de acesso à profissionalização, aos programas sociais e às vagas nas creches:

"[...] Se tivesse na secretaria um local para a gente referendar essas familias [...], para fazer um curso profissionalizante [...], podia fazer um curso profissionalizante [...]." (E26)

"E o programa do leite que a gente tem pra oferecer [...] é difícil para a gente [...], são poucas senhas por mês, a gente não consegue inscrever todas as crianças." (E26)

“A gente tem problemas de vagas nas creches [...]." (E36)

"Tem muita coisa que interfere bastante no desenvolvimento da criança: [...] escola, que às vezes não tem vaga." (E39)

Assim, nessa última categoria, considera-se que proteção social pode ser caracterizada pelo acesso dos cidadãos a serviços e benefícios certificados como direitos, como um conjunto de programas e ações dirigidos ao enfrentamento de diferentes níveis de privação, risco e vulnerabilidade ${ }^{(25)}$.

As falas aludem para situações em que a família não possui acesso a cursos profissionalizantes e à segurança alimentar e nutricional. A inflexão dialética mostrou que essa situação de falta de acesso reflete o baixo investimento público nas políticas de proteção social que, embora tenham sido regulamentadas no Brasil por uma legislação específica, ainda possuem recursos escassos aplicados nessa área. Esses programas sociais têm sido focalizados nos pobres, prestados, muitas vezes, por entidades privadas sem fins lucrativos e com pouco controle social ${ }^{(19,25)}$.

Embora as políticas de assistência social estejam sendo desenvolvidas em muitos municípios, contraditoriamente, elas têm sido preteridas no estabelecimento do orçamento para esse setor $^{(25)}$. Tal ausência de prioridade decorre provavelmente da austeridade no gasto público, que tem se caracterizado por restrições orçamentárias na dotação dos programas sociais nos países subordinados aos ajustes macroeconômicos ${ }^{(19)}$.

Os participantes, em outras falas, descrevem a falta de acesso à educação infantil. A inflexão dialética mostrou que essa lacuna revela a contradição presente na realidade nacional, que ainda não conseguiu ampliar, quantitativa e qualitativamente, as vagas na educação infantil, especialmente para as crianças de até três anos de idade ${ }^{(26)}$. 
A creche, instituição historicamente caracterizada pelo assistencialismo e precariedade, tem sido ressignificada como um ambiente de cuidado, educação e desenvolvimento integral da criança ${ }^{(27)}$. No Brasil, como em outros países em desenvolvimento, essa valorização está fortemente ligada ao processo de urbanização da população e à crescente participação das mulheres no mercado de trabalho ${ }^{(28)}$.

Um estudo mostrou que no Brasil, em 2007, somente $17,1 \%$ das crianças de 0 a 3 anos possuíam acesso à educação infantil ${ }^{(28)}$. Outra pesquisa descreveu que esse acesso tem sido garantido para apenas $21 \%$ das crianças brasileiras com idade-alvo para a educação infantil ${ }^{(25)}$, o que sinaliza uma contradição diante da legislação estabelecida e do discurso governamental de o Brasil ser uma pátria educadora. Tal contradição se aprofunda quando se compara a iniquidade de acesso à educação infantil entre as crianças das zonas urbana e rural, entre as brancas e pretas ou pardas, e entre as oriundas de famílias mais pobres e mais ricas ${ }^{(28)}$.

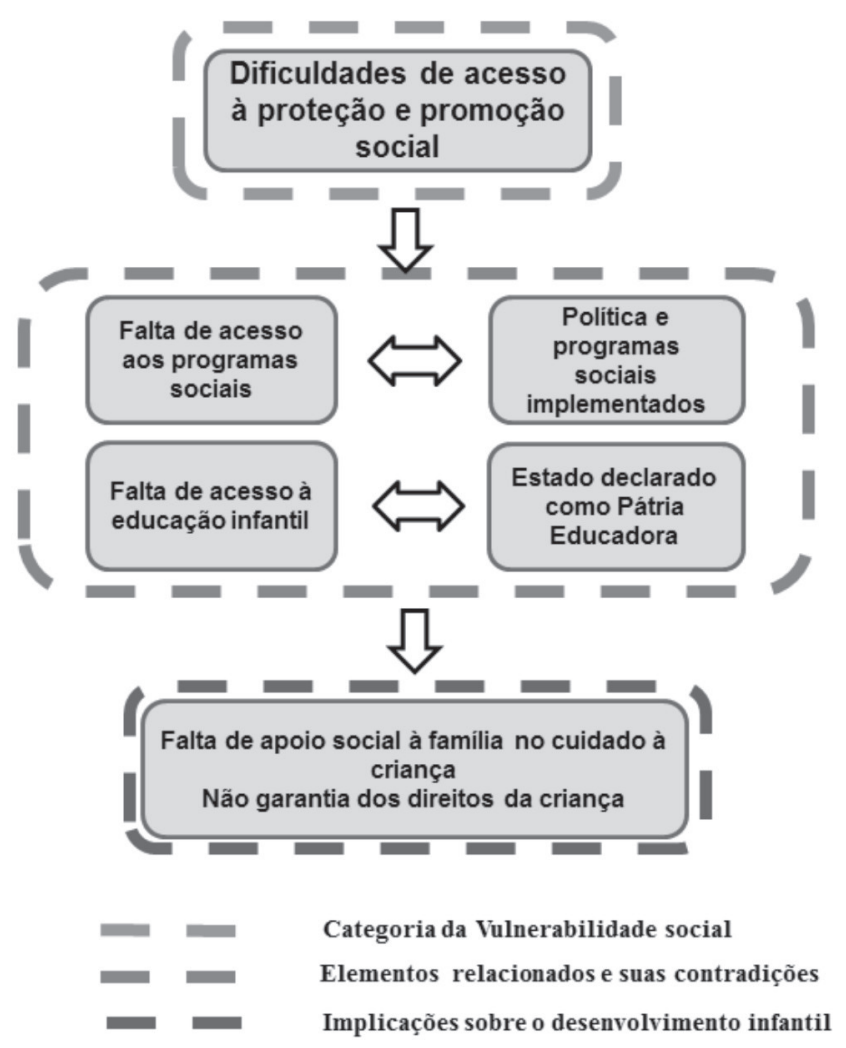

Figura 3 - Dificuldades de acesso à proteção e promoção social, elementos relacionados e contradições apreendidas com suas implicações sobre desenvolvimento infantil, segundo os enfermeiros da ESF. Curitiba-PR, 2012.

Segundo o Censo de 2010, em Curitiba, vivem cerca de 107.919 crianças menores de 5 anos, que teriam direito de acesso à educação infantil. No entanto, nota-se que somente 52\% (57.870 matrículas) desse universo está matriculado em alguma instituição, seja de natureza pública - 28\% (31.219 matriculas) - ou privada - 24\% (26.651 matrículas ${ }^{(29)}$. Essa situação remete aos baixos investimentos para ampliação do acesso à educação infantil, assim como à ocupação do espaço estatal pela iniciativa privada. Embora declare proteger a criança, o Estado, de forma contraditória, não garante os direitos fundamentais para a infância, devido aos ajustes macroeconômicos, que determinam menores investimentos em políticas públicas sociais ${ }^{(28)}$.

Sendo assim, a Figura 3 sintetiza o processo de inflexão dialética e depreende que as dificuldades de acesso à proteção e promoção social podem provocar falta de apoio social à família no cuidado à criança, assim como a não garantia dos direitos da criança de se desenvolver como cidadão e pessoa ${ }^{(10,30)}$.

\section{CONSIDERAÇÕES FINAIS}

O enfermeiro da Estratégia Saúde da Família compreende que a vulnerabilidade no desenvolvimento infantil está relacionada a elementos de ordem socioeconômica, caracterizados pelas iniquidades sociais. Tais iniquidades são descritas pela baixa inserção social da família, iniquidades da ocupação do solo e dificuldade de acesso aos direitos sociais. Sua compreensão da vulnerabilidade extrapola os componentes biológicos e individuais relacionados ao desenvolvimento infantil.

Os elementos apresentados determinam as condições materiais da família para garantir a subsistência, os direitos, o cuidado e o estímulo ao desenvolvimento da criança. No entanto, as falas expressam contradições, como a não universalidade do acesso à educação, as políticas macroeconômicas que determinam o desemprego e a baixa renda, a posse desigual da terra, a migração da zona rural para os grandes centros urbanos, as políticas sociais implantadas legalmente e não desenvolvidas e o discurso do Estado brasileiro como pátria educadora.

Os elementos de vulnerabilidade social relatados foram apreendidos como uma expressão do processo saúde-doença das famílias, que se manifesta nas limitações no cuidado à criança, destacando a premência de uma organização social inclusiva e igualitária que compartilhe seus recursos para o bem-estar de todos os cidadãos. As demandas sociais evidenciam que existe iniquidade na estrutura social e estatal, apresentando-se como incapaz de proporcionar às famílias as condições necessárias para a proteção e cuidado à criança.

Este estudo possui limitações, tendo em vista que foi realizado em apenas uma região do país e com um número limitado de pessoas, não refletindo a realidade em sua totalidade. Contudo, os resultados desta pesquisa poderão contribuir para a prática assistencial à criança e para a 
realização de novos estudos que busquem o avanço na estruturação e utilização do conceito de vulnerabilidade na área de Saúde da Criança.

\section{REFERÊNCIAS}

1. Beeckman K, Louckx F, Putman K. Predisposing, Enabling and Pregnancy-Related Determinants of Late Initiation of Prenatal Care. Matern Child Health J. 2011;15(7):1067-75.

2. Moreno-De-Luca A, Myers SM, Challman TD, MorenoDe-Luca D, Evans DW, Ledbetter DH. Developmental brain dysfunction: Revival and expansion of old concepts based on new genetic evidence. Lancet Neurol. 2013;12(4):406-14.

3. Turner HA, Finkelhor D, Ormrod R, Hamby S, Leeb RT, Mercy JA, et al. Family context, victimization, and child trauma symptoms: variations in safe, stable, and nurturing relationships during early and middle childhood. Am J Orthopsychiatry. 2012;82(2):209-19.

4. Piccolo LR, Falceto OG, Fernandes CL, Levandowski DC, Grassi-Oliveira R, Salles JF. Variáveis psicossociais e desempenho em leitura de crianças de baixo nível socioeconômico. Psicol Teor Pesqui. 2012;28(4):38998.

5. Shonkoff JP. Protecting brains, not simply stimulating minds. Science. 2011;333(6045):982-3.

6. Bronfenbrenner U. Bioecologia do desenvolvimento humano: tornando os seres humanos mais humanos. Porto Alegre: Artmed; 2011.

7. Silva DI, Chiesa AM, Veríssimo MLOR, Mazza VA. Vulnerability of children in adverse situations to their development: proposed analytical matrix. Rev Esc Enferm USP. 2013;47(6):1397-402.

8. Nichiata LYI, Bertolozzi MR, Gryschek ALPL, Araújo NVDL, Padoveze MC, Ciosak SI, et al. Potencialidade do conceito de vulnerabilidade para a compreensão das doenças transmissíveis. Rev Esc Enferm USP. 2011;45(Nesp 2):1769-73.

9. Pedroso MLR, Motta MGC. A compreensão das vulnerabilidades sócio-econômicas no cenário da assistência de Enfermagem pediátrica. Rev Gauch Enferm. 2010;31(2):218-24.

10. Mazza VA, Chiesa AM. Family needs on child development in the light of health promotion. Online Braz J Nurs [periódico na Internet]. 2008 [acesso em 2015 Abr 12];7(3). Disponível em: http://dx.doi. org/10.5935/1676-4285.20081852.
11. Chiesa AM, Westphal MF, Akerman M. Doenças respiratórias agudas: um estudo das desigualdades em saúde. Cad Saúde Pública. 2008;24(1):55-69.

12. Minayo MCS. O desafio do conhecimento: pesquisa qualitativa em saúde. 11ª ed. São Paulo: Hucitec; 2008.

13. Mustard JF. Free market capitalism, social accountability and equity in early human (child) development. Paediatr Child Health. 2008;13(10):839842.

14. Chaves MMN, Egry EY. Competência avaliativa do enfermeiro para reconhecer e enfrentar necessidades de saúde das famílias. Cogitare Enferm. 2013;18(4):72935 .

15. Nazarpour M, Branch M. Improving financial situation of rural women. Journal of American Science. 2012;8(9):499-504.

16. Ferraro AR. Escolarização no Brasil: articulando as perspectivas de gênero, raça e classe social. Educ Pesqui. 2010;36:505-26.

17. Soares MAT, Costa AB. Contradições acerca da redução da desigualdade social no Brasil. Argumentum 2011;3(1):157-70.

18. Ulyssea G. Informalidade no Mercado de trabalho brasileiro: uma resenha da literatura. Rio de Janeiro: IPEA; 2006.

19. Vazquez DA, Höfling DM, Cajueiro JPM, Monfredini MI. Política econômica e política social no Brasil nos anos 1990: possibilidades, limites e condicionantes. Economia Sociedade. 2004;13(2):147-67.

20. Arku G, Luginaah I, Mkandawire P, Mkandarwire P, Badien P, Asiedu AB. Housing and health in three contrasting neighborhoods in Accra, Ghana. Soc Sci Med. 2011;72(11):1864-72.

21. Cohen SC, Kligerman DC, Monteiro SCF, Cardoso TAO, Barcelos MRB. Habitação saudável como determinante social da saúde: experiências internacional e nacional. Rev Bras Promoç Saúde. 2011;24(2):16979.

22. Maldonado JL. Segregação Social e Mercados Habitacionais nas Grandes Cidades. Rev Continentes. 2013;2(3):73-97.

23. Ribeiro LCQ, Silva ÉT, Rodrigues JM. Metrópoles brasileiras: diversificação, concentração e dispersão. Rev Paranaense Desenvolvimento. 2011;120:177-207.

24. Maricato E. Globalização e política urbana na periferia do capitalismo. Territórios. 2008;18:183-205. 
25. Vaitsman J, Andrade GRB, Farias L. O. Proteção social no Brasil: o que mudou na assistência social após a Constituição de 1988. Ciênc Saúde Coletiva. 2009;14(3):731-41.

26. De Sordi JO, Nelson RE, Galindo PR. Problema da falta de vagas em creches: matriz de loops e a priorização de causas de problemas complexos. Rev Adm Pública. 2014;48(6):1407-30.

27. Araújo MAN, Gama FS, Silva U. Creche de ontem e de hoje: o que os pais esperam dessa instituição? Rev Psicol Diversidade Saúde. 2013;2(1):1-20.

28. Castro JA. Evolução e desigualdade na educação brasileira. Educ Soc. 2009;30(108):673-97
29. Instituto Paranaense de Desenvolvimento Econômico e Social. Caderno Estatístico: Município de Curitiba. 2012 [acesso em 2014 Maio 12]. Disponível em: http://www.ipardes.gov.br/cadernos/MontaCadPdf1. php?Municipio $=80000 \&$ btOk $=$ ok

30. Alexandre AMC, Labronici LM, Maftum MA, Mazza VA. Map of the family social support network for the promotion of child development. Rev Esc Enferm USP. 2012;46(2):272-9.

\section{Endereço para correspondência:}

Daniel Ignacio da Silva

Travessa Lorenzo Ratti, 3A

Bairro: Jardim da Saúde

CEP 04153-120 - São Paulo - SP - Brasil

E-mail: daniel.silva1076@usp.br 